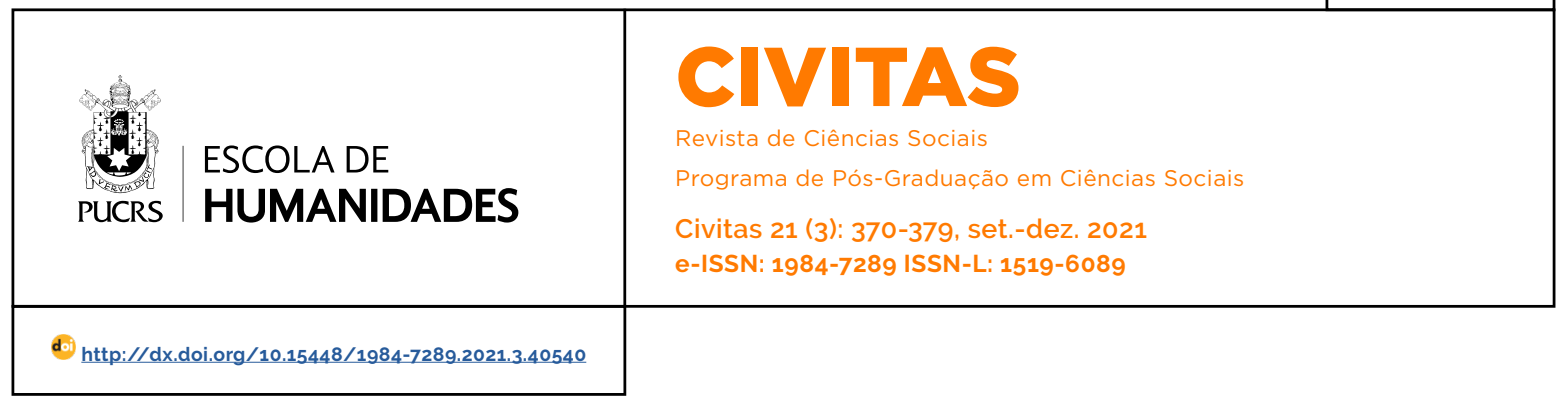

DOSSIÊ: INTERSECCIONALIDADES, DIREITOS E POLITIICAS

\title{
Marcadores sociais da diferença na experiência escolar de jovens estudantes negras
}

Social markers of difference in the school experience of young black women

Marcadores sociales de diferencia en la experiencia escolar de jóvenes alumnas negras

\section{Cristiane Barbosa \\ Soares ${ }^{1}$}

orcid.org/0000-0001-8008-5830

cristi.soa@gmail.com

Alinne de Lima Bonetti² orcid.org/0000-0003-0810-5926 alinne.bonetti@gmail.com

Recebido em: 31 mar. 2021 Aprovado em: 20 jul. 2021 Publicado em: 8 nov. 2021
Resumo: Analisamos os marcadores de gênero e raça presentes nas experiências de jovens estudantes negras de uma escola da rede pública. Para tanto, utilizamos a abordagem etnográfica a fim de compreender como tais marcadores operam no processo de construção das subjetividades das jovens negras. Com isso, questões sobre identidade, representatividade e resistências surgiram se inter-relacionando no processo de construção das subjetividades, o que evidenciou a emergência dos marcadores de gênero e de raça nas dinâmicas estabelecidas no contexto escolar. A partir dessa leitura, depreendemos que as experiências dos sujeitos que transitam no contexto escolar reforçam a importância da escola no processo de construção das subjetividades.

Palavras-chave: Escola. Gênero. Raça. Interseccionalidade.

Abstract: We analyzed the gender and race markers present in the experiences of young black students at a public school. For this, we use the ethnographic approach in order to understand how such markers operate in the process of building the subjectivities of young black women. With this, questions about identity, representativeness and resistance emerged interrelating in the process of building subjectivities, which evidenced the emergence of gender and race markers in the dynamics established in the school context. From this reading, we understand that the experiences of the subjects who transit in the school context reinforce the importance of the school in the process of building subjectivities. Keywords: School. Gender. Race. Intersectionality.

Resumen: Analizamos los marcadores de género y raza presentes en las experiencias de jóvenes estudiantes negros en una escuela pública. Para ello, utilizamos el enfoque etnográfico con el fin de comprender cómo operan dichos marcadores en el proceso de construcción de las subjetividades de las jóvenes negras. Con ello surgieron interrogantes sobre identidad, representatividad y resistencia inter-relacionados en el proceso de construcción de subjetividades, lo que evidenció el surgimiento de marcadores de género y raza en las dinámicas establecidas en el contexto escolar. De esta lectura inferimos que las vivencias de los sujetos que transitan en el contexto escolar refuerzan la importancia de la escuela en el proceso de construcción de subjetividades.

Palabras clave: Escuela. Género. Raza. Interseccionalidad. 


\section{Apresentando o tema}

A partir de Neusa Souza (1983), entendemos que não nascemos negras, tornamo-nos através da tomada de consciência de toda a opressão de gênero e raça que atravessa nossos corpos desde muito cedo. Esse processo se dá em diferentes espaços sociais, entre os quais se destaca a escola, atravessada por conflitos e construções sociais que envolvem aspectos socioculturais, políticos, econômicos e raciais, com papel importante no combate às opressões e para a emancipação dos grupos discriminados. Ao mesmo tempo, entendemos que a educação é um processo para além da escola, é ensino, prática, política, que produz conhecimento e promove a liberdade. $\mathrm{E}$ a Lei 10.639/2003 ${ }^{2}$ inaugura um cenário para o reconhecimento e a valorização da história e da cultura afro-brasileira a partir da educação, o que impacta diretamente no processo de construção das subjetividades das pessoas negras.

Neste sentido, importa destacar que a identidade racial envolve mais que ter determinado tom de pele; implica em possibilidades de ressignificação, de revisão histórica de sua própria condição e, sobretudo, de se narrar reflexivamente a partir de novas posições de sujeito (Gomes 1996). Frente a esse quadro, partindo da experiência docente de uma das autoras, mulher negra, junto a um grupo de estudantes de uma escola pública, identificamos a necessidade de compreender e de problematizar como os processos de subjetivação se dão no ambiente escolar, atentando para a experiência de identificação e de produção de subjetividades de jovens negras.

Assim, neste artigo analisamos alguns dos resultados oriundos da pesquisa "Marcadores sociais da diferença e a produção de subjetividades: mulheres negras na Educação Básica", que teve como foco de análise as convenções de gênero e de raça (re)produzidas no contexto escolar. ${ }^{3}$ Dessa forma, remetemos nossos olhares às jovens estudantes negras e procuramos compreender como o ambiente escolar, seus discursos e suas práticas têm colaborado para o processo de reconhecimento dessas jovens enquanto mulheres e negras.

\section{Cenário de articulações}

Em um pais estruturado pelo racismo (Nogueira 2006) associado ao sexismo (Gonzales 1984), o branqueamento 4 (Jaccoud 2008) é um valor e um modelo que se deve atingir. Ao internalizar uma autoimagem negativa, reforçada, por exemplo, por uma mídia que exalta um padrão de beleza e reserva lugares subalternos às mulheres negras, essas buscam embranquecer-se; entretanto, como padrão impossivel de ser atingido, torna-se uma forma de violência que impacta o processo de subjetivação de muitas mulheres negras. Observa-se, então, a operação das imagens de controle da condição da mulher negra (Collins 2019); um esforço em produzir um padrão ideal de mulher negra a partir de sua objetificação como o Outro. Um processo social que, diante da realidade do racismo e do sexismo, impõe às jovens negras posições de desvantagens frente às expectativas educacionais, profissionais, afetivas, entre outras.

\begin{abstract}
O racismo se constituiu e opera essencialmente da mesma forma que o sexismo, tanto no campo da discriminação, resultando em desigualdades sociais estatisticamente mensuráveis, quanto no âmbito mais amplo, efetuando de diversas maneiras, ora diretas, ora sutis, determinações e condicionamentos às possibilidades e às perspectivas de vida das pessoas e dos grupos humanos envolvidos. (Nascimento 2003, 66).
\end{abstract}

Assim, a fim de investigar as convenções de gênero e raça no espaço escolar, nos preocupa-

\footnotetext{
2 Brasil, 2003. Ministério da Educação: Lei n 10.639 de 09 de janeiro de 2003. Diário Oficial da União, 1 jan. 2003. Acessado em 10 jul. 2021, https://www.planalto.gov.br/ccivil_03/leis/2003/l10.63.9.htm

3 Cabe destacar a proeminência do marcador geracional na constituição do universo analítico. Entendemos que geração "designa um coletivo de indivíduos que vivem em determinada época ou tempo social, tem aproximadamente a mesma idade e compartilham alguma forma de experiência ou vivência" (Britto da Motta 2004, 350). Neste sentido, a referência às interlocutoras a partir da sua posição geracional - juventude - está diretamente associado com o processo de socialização escolar e articulação dos marcadores de gênero e raça na sua subjetivação.

4 A tese do branqueamento baseia-se na "aceitação da perspectiva de existência de uma hierarquia racial e o reconhecimento dos problemas imanentes a uma sociedade multirracial somaram-se a ideia de que a miscigenação permitiria alcançar a predominância da raça branca" (Jaccoud 2008, 49).
} 
mos em observar a interseccionalidade desses marcadores no que diz respeito ao processo de construção das subjetividades das jovens estudantes negras, a partir de pesquisa etnográfica, marcada pela observação participante, com registros sistemáticos em diários de campo (Cardoso de Oliveira 1998) ao longo da interação diária de uma das autoras, docente do grupo de estudantes, entre o período de 30 de agosto de 2017 a 13 de dezembro de 2017.

Como interlocutoras da pesquisa contamos com 15 estudantes, sendo 13 meninas, com idade entre 12 e 15 anos, da etapa do ensino fundamental de uma escola pública municipal localizada em bairro periférico de baixa renda de Uruguaiana, RS. No que tange à classificação étnico-racial, foco desta análise, oito estudantes - sete meninas foram identificadas como negras considerando suas características fenotípicas e a cor de pele. Importa informar que, de modo a preservar o anonimato das interlocutoras da pesquisa, em acordo com os preceitos éticos que regem a pesquisa etnográfica, identificamo-las com os nomes de rainhas do continente africano a partir de matéria do Portal Geledés. ${ }^{5}$ O corpus de análise é composto por 42 registros em diários de campo, que foram submetidos à análise de conteúdo, da qual se constituiram três categorias analíticas em torno das quais se pode compreender a experiência de subjetivação das jovens negras atravessadas por convenções de gênero e de raça: identidades; representatividade; e resistências.

Destacamos que a subjetividade não deve ser entendida como interioridade ou capacidade latente; antes é constituida por relações e ligações que produzem sujeitos como agenciamentos, ou seja, "a subjetividade - o lugar do processo de dar sentido a nossas relações com o mundo - é a modalidade em que a natureza precária e contraditória do sujeito-em-processo ganha significado ou é experimentada como identidade" (Brah 2006, 371).

Nesse sentido, as identidades tendem a ser constantemente remodeladas no processo das relações sociais, tornando-se fluidas, cambiantes e contraditórias. Assim, são "produzidas em locais históricos e institucionais específicos, no interior de formações e práticas discursivas específicas, por estratégias e iniciativas especificas" (Hall 2012, 109). Identidades são construções associadas a discursos, práticas e posições do sujeito em interação com dispositivos históricos de poder e de resistência em processos sociais de construção de hegemonias, as quais "passam a ser consideradas como expressão da realidade social" (Louro 2000, 9).

Narrativas e padrões hegemônicos foram construidos historicamente sob a ótica eurocêntrica, que estabeleceu como padrão de normalidade o masculino, branco, heterossexual e cristão. Assim, os sujeitos que não se enquadram nesse padrão são considerados os outros e excluidos socialmente, juntamente com o silenciamento de sua história e a invisibilidade de sua cultura (Louro 2000). E, é a partir dessa perspectiva que o termo representatividade se incorpora, na medida em que esses sujeitos rompem a fronteira da invisibilidade, ocupam os espaços que lhes foram negados e tornam-se modelos que representam "os outros" e mostram outras possibilidades de existência.

Ao mesmo tempo, o conceito de resistência vem como prática emancipatória do sujeito, permitindo, enquanto grupo oprimido, a criação de estratégias para transitar entre as verdades impostas e, ao mesmo tempo, refletir e questioná-las. Assim, resistência configura-se como um modo de "enfrentar os sistemas de dominação/exploração baseados em gênero, raça e classe social" (Meneghel, Farina e Ramão 2005, 571) que rompe com a visão hegemônica de mulher universal, deslocada das dimensões de raça, gênero e classe.

Cumpre também explicitar as principais ferramentas conceituais utilizadas na análise. Para tanto, compreendemos que marcadores da diferença se referem a um conjunto de valores histórica e socialmente constituidos de variáveis, tais como gênero, sexualidade, raça, geração, entre outros, que atuam nos processos de diferenciação social e de posicionamento dos

Geledés. 2014. Grandes reis e rainhas da África. Plano de aula, 4 jun. 2014. Acessado em 13 ago. 2020, https://www.geledes.org.br/ grandes-reis-e-rainhas-da-africa. 
sujeitos na estrutura social. Entendemos raça como construção política e social; uma categoria discursiva articulada à prática de hierarquização social das pessoas segundo a cor da sua pele e traços fenotípicos (Gomes 2012). Convenções de gênero são entendidas como o "conjunto de valores e ideais relativos ao imaginário sexual disponiveis na cultura e compartilhados, a partir dos quais os seres sociais pautam as suas ações e concepções de mundo, reproduzem e recriam estas mesmas convenções e as suas práticas" (Bonetti 2011, s.p.). Ainda, destacamos a interseccionalidade como combinatória particular de diversos marcadores sociais da diferença que resultam ou podem resultar em desigualdade, dependendo do contexto das relações sociais envolvidas (Brah 2006), conceito fundamental para as articulações desta pesquisa.

Assim, analisaremos as convenções de gênero e de raça a partir das categorias: Identidades; Representatividade e Resistências.

\section{Identidades}

Em uma sociedade em que a identidade é mutável, instável e plural, mas ao mesmo tempo nos faz pertencer a um grupo, associada aos diferentes espaços sociais do qual o sujeito participa e se referencia (Hall 2004), a identidade racial é apenas uma construção possivel. Com isso, entendemos que nossas identidades estão constantemente em disputa, em um sistema de relações e de representações para nós e para os outros. E, diante da depreciação que sofre nos múltiplos espaços, a mulher negra é estimulada a negar sua negritude, colocando em xeque sua identidade racial.

Compreendendo a escola como uma das instâncias responsáveis pelo processo de construção das identidades raciais e de gênero dos sujeitos que transitam nela, é importante observarmos os discursos que circulam em suas práticas. Percebemos, ao analisar o currículo de uma escola, suas intencionalidades expressadas pelos seus discursos e as orientações das ações pedagógicas. Contudo, para acionar comporta- mentos e disciplinar os sujeitos a partir de valores, normas, discursos e saberes que corroborem as identidades que objetivam produzir, deverá organizar-se pedagogicamente.

Partindo dessa compreensão, a imersão no contexto da escola nos permitiu observar situações que explicitam os discursos contidos no currículo. Discursos que interpelam a comunidade escolar que, a partir de suas interpretações cercadas de valores e normas morais, o acionam no cotidiano escolar a fim de disciplinar, como destacado nos extratos das observações de campo, a seguir: Kahina 6 - menina negra - vem direto a mim e
começa a relatar e, de certa forma, também
reclamar sobre o que havia acontecido com
ela. Disse que passou um batom bem forte e
veio para escola "se achando". Entretanto, ao
entrar a guarda escolar já falou que o batom
"era muito forte para idade dela", ela não se
importou e subiu para a aula. Ao subir as es-
cadas, uma professora a chama e a faz ir ao
banheiro retirar o batom, pois "aquele batom
não era adequado para a escola". Ela foi até o
banheiro, tirou o batom e retornou sem ques-
tionar e sem falar mais nada. Mas, mesmo
sem questionar a forma como foi conduzida a
situação sua atitude, ao relatar o fato ocorrido,
demostrava o seu incomodo em não poder
usar o batom que ela queria e achava bonito.
Não sabia o que fazer e com o batom na mão,
me dizia sorrindo "tô louca para passar isso".
(Notas de campo, 16 nov. 2017).

[...] chego para dar aula e surge o papo sobre roupa, pois algumas ali não sabiam que obrigatoriamente deveriam estar usando ao menos uma peça do uniforme escolar. No meio de tantas opiniões e certezas do que vestirem, surge um relato que despertou minha atenção pela forma como a situação foi conduzida a fim de disciplinar e regular a menina a partir da sua vestimenta. Dizia ela "Outro dia vim com um short bem por aqui Imostrando que o comprimento era acima do joelho] e dai a 'sôra' lá mandou voltar para casa e colocar algo mais decente. Ela disse que eu não ia entrar na sala daquele jeito. Ouvi aquilo, fui pra casa e não voltei, fiquei olhando TV com meu irmão". ([Yalla7 - não negral, Notas de campo, 7 nov. 2017).

Percebemos, nesses extratos, o quanto os sujeitos, partindo de suas convenções, normatizam e

\footnotetext{
Kahina foi princesa e profetisa berbere, é considerada heroína nacional na Argélia, símbolo da resistência berbere.

Yalla foi rainha do reino de Waalo, atual Senegal, lutou contra a colonização francesa.
} 
regulam aquilo que é permitido e aquilo que não é. Reforçando determinados comportamentos e preconceitos acabam instituindo aquilo que é correto e aquilo que não é para o funcionamento da dinâmica social na escola. Nos casos apresentados, tanto as professoras quanto a guarda-escolar reforçaram modos de feminilidade hegemônicas a partir de convenções de gênero mais tradicionais e esses discursos refletem-se na constituição das identidades dessas jovens, pois, "nenhuma identidade é construida no isolamento. Ao contrário, é negociada durante a vida toda por meio do diálogo, parcialmente exterior, parcialmente interior, com os outros" (Gomes 2005, 42).

Para Gomes (2005), todo e qualquer processo identitário depende das relações dialógicas, do diálogo aberto, da troca com o outro. Destarte, a reflexão sobre a construção da identidade racial não pode deixar de levar em conta a discussão sobre a identidade enquanto processo mais amplo e complexo. Retornamos aos achados de campo, em situações que as estudantes mostraram não reconhecer sua identidade.

Com a aproximação da semana da consciência negra, puxo o tema para uma roda de conversa. Expliquei o que aconteceria naquele momento, que seria uma conversa onde poderiam ficar à vontade e expressar o que quisessem. Uma das estudantes não-negra relata que gostaria de ser negra pois acha o "tom da pele lindo" - ao falar aponta para Nanny ${ }^{8}$, que é fenotipicamente negra. Seguindo a conversa, Makeda ${ }^{9}$, menina negra, diz que é até "escurinha", mas que acha que é do sol mesmo. Já Nanny relata que não sabe o que é, pois nunca pensou nisso, mas que acha que não é negra; de pronto Kahina a interrompe e diz "Mas, é claro que somos negras, né guria!" - percebo que Nanny fica pensando sobre aquilo, mas não fala mais nada. (Notas de campo, 6 nov. 2017).

A identidade negra se constrói em um movimento que envolve inúmeras variáveis, desde as primeiras experiências estabelecidas no grupo social mais intimo, onde os contatos pessoais se estabelecem permeados de sanções e de afetividades e em que se elaboram os primeiros ensaios de uma futura visão de mundo. Entretanto, conforme destaca Brah (2006, 362), o significado dado a estas experiências varia de um individuo para outro.

Quando falamos da constituição do individuo para sujeito através de múltiplos campos de significação estamos invocando inscrição e atribuição como processos simultâneos através dos quais o sujeito adquire significado em relações socioeconômicas e culturais no mesmo momento em que atribui significado dando sentido a essas relações na vida cotidiana.

Entendendo que a atribuição de significado de uma pessoa para um determinado evento varia conforme ela é construída culturalmente, resgatamos duas situações.

Organizando alguns cartazes sobre a mulher negra, para exposição da escola, as meninas explicavam o que queriam mostrar e apontam a Nanny como um exemplo de menina negra na escola, mas Nanny dizia: "Eu não sou preta 'sôra'!". (Notas de campo, 19 out. 2017).

Saio do prédio da escola com um grupo de estudantes que logo se dispersam, assim sigo caminhando pelo pátio e em certo momento paro para conversar com Idia ${ }^{10}$. Logo, percebo que Makeda está sentada perto de nós e a chamo para conversar conosco, mas, ela, diz: “- eu não vou pro o sol 'sôra', não quero ficar preta" [sendo fenotipicamente negra]. (Notas de campo, 31 out. 2017).

Em ambos os casos as meninas negam as marcas da negritude em si a partir das convenções de raça que entendem baseadas nas suas influências socioculturais. E, com isso, não reconhecem sua negritude. Assim, não podemos determinar que a prática de atribuir sentido às nossas experiências opera de maneira isolada, fora daquilo que vivemos com o mundo e com os outros. Mas, faz parte de um "campo de significação e representação que estão em jogo na formação de sujeitos diferentes" (Brah 2006, 361). Portanto, atribuir significados às nossas experiências não é algo dado e harmonioso de um dia para o outro, mas é parte de um longo processo de compreensão de si.

\footnotetext{
8 Nanny foi líder dos Marrons Windward da Jamaica, que foi considerado uma das maiores potências militares da terra entre 1724 a 1739

9 Makeda, o verdadeiro nome da rainha da Etiópia, a esposa de Salomão rei da Judéia, conhecida como Rainha de Sabá.

- Idia foi uma rainha e guerreira que lutou incansavelmente antes e durante o reinado de seu filho como o Oba (rei) do povo Edo.
} 
[...] com apenas meninas na sala acredito que será possivel uma ótima discussão sobre a entrevista do programa "Conversa com Bial"11, que trouxe para nosso diálogo sobre o protagonismo de mulheres negras. [...]. No início do programa Karol Conka canta "Bate a Poeira" e todas cantam do início ao fim. Atenta em cada uma delas percebo os olhares fixos na entrevista. Após o vídeo pergunto se alguém quer falar ou comentar alguma coisa, Cleópatra ${ }^{12}$ após assistir a fala de Eliane Dias, com Karol Conka e outras mulheres negras sobre representatividade e preconceitos, disse que nunca pensou sobre ser ou não negra, pois ninguém nunca disse nada para ela e que aquilo nunca fez diferença. Reconheceu que mesmo assim ela 'mexia' com muitas meninas as chamando de 'preta'- 'macaca' e só agora se deu conta que ela também estava falando mal de si (Notas de campo, 13 dez. 2017).

Ao relatar sua experiência, Cleópatra mostra a capacidade de reflexão a partir da possibilidade de interação com outras influências socioculturais. Podemos perceber aqui a importância da prática reflexiva para atribuição de significados às experiências, sejam elas individuais ou coletivas.

Diante dos cartazes da semana da consciência negra Nanny negava sua identidade racial, enquanto Kahina ressaltava que era preta e que sentia orgulho de ser. Dizia Kahina que não havia como negar, já que a sua cor era aquela e não admitia que falassem algo preconceituoso que ela já "batia boca". Aproveito o momento e pergunto se foi sempre assim, esse orgulho e essa certeza de ser quem é, e ela responde que não e que nem sabia que existia "esse preconceito" até assistir na "Malhação" (novela com temática adolescente da Rede Globo) e ver o que a personagem passou por ser preta. E só isso a fez perceber que deveria sentir orgulho de quem era, bem como fez aquela personagem. (Notas de campo, 19 out. 2017).

Ao retornar para sala de aula encontro-me incomodada com algumas práticas que observo. Assim, largo os materiais de uma aula programada e, na tentativa de problematizar aquela "brincadeira" que estavam reproduzindo, discutimos sobre preconceito e discriminação. Sentamos em roda, conversamos sobre a importância das diferenças na sociedade e que não sabemos conviver com elas. Remeto-me à situação que ocorreu e que vejo reproduzidas no cotidiano escolar. Tentam justificar suas práticas como "brincadeiras", dizem que não fazem e que não tem preconceito, se expressam até a fala da Amina13: "Lá na minha casa, todos são assim [apontando para sua pele negra] e a minha mãe sempre disse que eu tenho que ter é orgulho de quem eu sou e não me importar com o que os outros vão falar de mim. Aqui no colégio todo mundo é diferente, mas ninguém se toca disso, né?! Porque sempre tem uns que se acham mais do que os outros, sempre tem". (Notas de campo, 27 out. 2017).

Nesses extratos percebemos as influências na constituição identitária das jovens. Tanto Kahina quanto Amina constroem as identidades raciais a partir da interação que as afeta. Na fala de Kahina percebemos a importância da instância midiática que foi determinante para sua afirmação enquanto negra; já na fala da Amina a figura materna da mulher negra foi determinante para tal afirmação e, cabe ressaltar, a preocupação dessa mãe com o racismo que a filha poderia enfrentar.

Tais extratos de campo nos possibilitam observar a interferência de espaços como a escola, a televisão e a família. O tempo de escola, por exemplo, ocupa um lugar privilegiado na vida das jovens negras e, esse tempo, registra lembranças, produz experiências e marcas profundas naquelas que têm a oportunidade de transitar por estes espaços. Como destacado, há uma diversidade de processos que possibilitam a construção das subjetividades, os quais perpassam a negação, a reflexão e a identificação, para assim atribuir sentido e significado às suas experiências mais cotidianas.

\section{Representatividade}

O sujeito se constrói na relação de suas experiências individuais, de suas vivências de mundo e com o outro. Tal processo tem influência da familia, escola e de outras relações sociais que se ramificam e corporificam os sentidos das experiências mais cotidianas. Entretanto, é ne-

\footnotetext{
11 No programa "Conversa com Bial", da Rede Globo de Televisão, o entrevistador debate com a ex-consulesa da França Alexandra Loras, a cantora Karol Conka, a estudante de cinema Yasmin Tainá, a produtora do Racionais Eliane Dias e MC Soffia sobre a luta das mulheres negras na música, arte e na sociedade. Globoplay. 2017. Programa Conversa com o Bial, 23 julho 2017. Acessado em 13 dez. 2017. https://globoplay.globo.com/v/5890376.

12 Cleópatra foi rainha do Egito, a última governante ativa do reino Ptolemaico do Egito.

13 Amina foi uma rainha guerreira muçulmana Hausa de Zazzau, atual norte da Nigéria.
} 
cessário refletir sobre as experiências que nos atravessam, pois como destaca Gomes (1996, 76), "desde o início da trajetória escolar, a criança se depara com um determinado tipo de ausência que a acompanhará até o curso superior [...]". E a invisibilidade também produz subjetividades, que imbricadas ao racismo e ao sexismo, fazem com que jovens negras não enxerguem suas potencialidades e neguem sua identidade racial.

Nessa perspectiva, a categoria Representatividade emerge demonstrando as potencialidades ocultas no contexto escolar e que se revelaram como um fenômeno que colabora com o processo de construção das subjetividades. O que reforça nossa compreensão sobre a complexidade desse processo, uma vez que a subjetividade "não é nem unificada, nem fixada, mas fragmentada em processo" (Brah 2006, 368). Esse processo se constrói na intersecção de muitas outras variáveis, que perpassam pela cultura, por discursos, costumes, comportamentos, padrões, entre outros, que podem ser incorporadas por ele.

A entrevista do programa "Conversa com Bial" parece ter despertado algumas vivências das meninas, pois, ao serem questionadas sobre a representatividade da mulher negra, muitas olham para sua familia e relatam o que sua mãe, avó, irmã e tia representam. Yalla fala que não é por não ser negra que ela não entende e não se importa com esses assuntos, mas que como pessoa deve questionar em casa e na escola o que é apresentado para ela como modelo. Idia conta que sua avó é negra e que ela se sente bem na escola, mas que em muitos lugares ela nem entra porque diz que não é lugar para ela. Com isso, Cleópatra também conta ter ido ao centro da cidade. certa vez, e que queria entrar em uma loja, mas não entrou por vergonha e só agora entendeu o porquê daquilo. Nzinga ${ }^{14}$ fala que em casa a familia é toda negra, mas às vezes esquece disso e, em outros lugares, vê que tem gente que olha torto e diferente para ela. (Notas de campo, 13 dez. 2017).

Enquanto a falta de representatividade é apontada, percebemos o quanto as mulheres da familia exercem um papel fundamental na constituição dessas jovens. Seja na autoestima ou em seu pertencimento racial as mulheres negras da familia têm provocado ressignificações positivas em seu cotidiano. Ao mesmo tempo, tais relatos apontam para uma prática pedagógica que busca produzir reflexões sobre as questões de gênero e de raça a fim de romper com a visão tradicional e estereotipada sobre a mulher negra.

No desenvolvimento dessa análise, notamos a importância de estratégias pedagógicas para o enfrentamento e o combate ao racismo e ao sexismo. Ao apresentar mulheres negras em espaços de produção de saberes, políticos e sociais, possibilitamos outros olhares. Com isso, as jovens negras podem constituir sua autoimagem e autoestima a partir de elementos de representatividade que sejam positivos.

\begin{abstract}
Durante a primeira conversa com a equipe diretiva da escola, tive a oportunidade de esboçar as intencionalidades do projeto e meus anseios. Assim, uma das professoras relata o seguinte: "Uma coisa que eu notei desde que as gurias começaram a trabalhar aqui, no caso tu [referindo-se a mim pesquisadora] e a X [professora negra], é de como as gurias começaram a mostrar mais os cabelos, a andar com eles mais soltos. Tu desfilando com aqueles turbantes lindos e a $X$ jogando aquelas 'madeixas crespas na cara da gente' [rindo]. Nunca havia reparado nisso, mas desde o ano passado vejo o quanto vocês influenciaram nesse aspecto". (Notas de campo, 30 ago. 2017).
\end{abstract}

Esse relato resume a importância da representatividade de forma positiva. Uma vez que as pedagogias que moldam nossas práticas transitam em várias instâncias, é fundamental problematizar que tipos de verdades são legitimadas a partir das convenções de gênero e de raça reproduzidas. Mostrar possibilidades que vão além de estereótipos é potencializar o campo de significações que atravessa os processos de subjetividades, além de romper com a visão racista que atravessa o imaginário social.

\section{Resistências}

Para que a imbricação do racismo e do sexismo, opressões que estruturam a sociedade, não 
se constituam em sentimentos de inferioridade e de desprezo pelas identidades raciais e de gênero, é necessário que os sujeitos mobilizem estratégias que promovam a coexistência ao nosso redor (Ribeiro 2017). Com isso, destacamos o seguinte registro de campo.

Encontro algumas meninas aparentemente inquietas, questiono o que está acontecendo. Uma delas conta que foi levada para a sala da direção, pergunto sobre a situação e ela explica que estava chegando na escola logo que soou o sinal ljá que mora perto ela não vai cedol e que a guarda a viu e, como outras pessoas também estavam entrando, ela não se apressou. Logo que olhou para a guarda, ela fecha o portão "na cara dela" e, mesmo pedindo para entrar, a guarda escolar não o abriu. Então esperou insistindo para que abrissem e nada, até que resolveu pular o portão lateral. Nesse momento a coordenadora de turno a flagra em cima do portão e a leva à direção. Já na direção ela conta tudo o que aconteceu e faz a diretora chamar a guarda escolar, mas relata que não adiantou nada, já que era a palavra dela contra a da outra. E desabafando diz: "mas 'sôra', só por que eu sou preta e pobre ela acha que pode me tratar como quiser? Se ela acha que vou baixar a cabeça ela tá muito enganada! Por que os outros ela deixou entrar numa boa e quando eu estava quase perto ela fez isso? Eu sou menos que os outros? Vou na direção quantas vezes for, mas não vou ficar quieta quando eu sei que não sou a errada". ([Kahina], Notas de campo, 30 out. 2017).

O extrato mostra a operação da imbricação de gênero e de raça em uma prática cotidiana, ao explicitar o motivo de ser impedida de entrar normalmente como as(os) demais. Ao narrar sua história, Kahina ressignifica aquilo que experienciou e, em uma ação reflexiva, coloca em xeque a prática adotada pela guarda-escolar. Remetendo ao fato, encontramos apoio nas palavras de Audre Lorde, ao descrever que "a fim de sobrevivermos, aqueles de nós para quem a opressão é extremamente comum, devem sempre estar vigilantes, tornarem-se familiares com a linguagem e as maneiras do opressor [...]" (Collins 2016, 113).

Nanny conta que gosta de um menino, mas que ele já disse que não gosta dela. No entanto, assim que ela fala, as meninas dão risadas, pergunto o que houve e elas falam: ' claro né sôra, claro que ele não vai gostar dela. Olha pra ela'. [Eu, indago, querendo que elas declarem aquilo que está ali velado] e concluem: 'ela é assim, louca'. Não verbalizam, mas a expressão para aquele contexto da conversa seria: "por que ela é preta', mas a intenção ficou nitida desde que elas a olharam dos pés a cabeça. $\mathrm{E}$ a Nanny responde: "- Olha quem tá perdendo tudo isso é ele!" [e passa a mão da cabeça até a cintural. (Notas de campo, 16 out. 2017).

Partindo da premissa de Audre Lorde (Collins 2016), para sujeitos que têm a opressão como normalidade, assim como Kahina, Nanny adota estratégias para enfrentar tal situação. Assim, os conflitos vão configurando as formas de resistência dessas jovens. Entretanto, a partir das emergências de cada contexto estes vão sendo ressignificados e, assim, atribuindo novos sentidos para que os sujeitos possam "ter alguma ilusão de proteção" (Collins 2016, 113).

Vejamos outra situação de campo:

Durante a mostra pedagógica muitos trabalhos estão expostos e alguns deles trazem pessoas negras em espaços de trabalho. Turmas para lá e para cá, num entra e sai de observações e comentários, percebo duas meninas conversando sobre suas expectativas de trabalho olhando um cartaz com mulheres negras "poderosas", quando passa um menino e diz: "nem adianta que tu não vai ser ela nunca" [havia a figura de uma jogadora de tênis negral. De pronto Califia ${ }^{15}$ se vira e ele sai correndo, mas eu estou por ali e ela fala comigo "Eu sei que eu sou neguinha, mas isso não tem nada a ver com o que eu posso ser como pessoa. Tenho para mim que as pessoas julgam muito o que podemos ser por conta do que a gente tem e o tipo de roupa que a gente veste. Tem muita gente que vem aqui no colégio e olha torto para gente, acha o quê?! Minha tia fala 'vamos tudo para o mesmo buraco' [risos] e que não deixe ninguém dizer o que eu posso ser". (Notas de campo, 22 nov. 2017).

Percebemos a estratégia de resistência se articulando à experiência escolar dessa jovem. O interessante nessa situação é a presença marcante, mais uma vez, de uma mulher da familia. As mulheres da família estão presentes nos relatos das interlocutoras e o que demostra a influência 
significativa dessas mulheres para o processo de produção de subjetividades dessas jovens.

Destarte, denominariamos que resistir é o primeiro verbo ensinado à juventude negra, antes mesmo de chegarem aos bancos escolares, e que se ressignifica nas vivências das mulheres negras. Visto que, diante da imbricação de gênero e de raça, é preciso resistir frente às opressões diárias para continuarem existindo. Assim, frente a conflitos e tensões, os sujeitos tendem a ressignificar suas próprias experiências, criando estratégias para o enfrentamento da violência racial e de gênero a fim de seguirem constituindo suas subjetividades, ou seja, reexistindo.

\section{Os (des)caminhos das subjetividades no espaço escolar}

Ao articular raça, gênero e classe, a mulher negra e pobre é posicionada e subjugada em um contexto de subalternidade e, dessa forma, necessita romper com a estrutura que a invisibiliza enquanto sujeito. Nesse contexto, seria insuficiente analisarmos as experiências das interlocutoras apenas centradas em um tipo de marcador da diferença.

Como percebemos, o marcador geracional emergiu dessas experiências, a partir da presença das ascendentes mulheres das jovens, mostrando sua potência com a articulação entre gênero, raça e classe para a construção das subjetividades dessas jovens, atribuindo-lhes representação positiva à identidade racial e à resistência frente aos processos que atravessam as vivências de mulheres negras. Dessa forma, destacamos a importância de práticas e escuta pedagógica sensiveis a esses marcadores, a necessidade de espaços de reflexão na escola para ações que rompam com os estereótipos alimentados pelo imaginário social e que estimulem a representatividade positiva para o que rege as relações raciais, sociais e de gênero.

Ressaltando a participação do contexto escolar no complexo processo de construção das subjetividades, percebemos que na escola não se aprende apenas a reproduzir as representações negativas do que é ser mulher negra, mas também se aprende a superá-las. Contudo, esse processo é reflexivo e deve perpassar o currículo e os debates pedagógicos, assim como prevê o parecer para as Diretrizes Curriculares Nacionais para a Educação das Relações Étnico-Raciais e para o Ensino de História e Cultura Afro-Brasileira e Africana, CNE/CP 003/2004. ${ }^{16}$

Ao traçarmos os rumos finais deste artigo é importante destacar que identidade, representatividade e resistências, ao mesmo tempo em que operam de forma independente, se articulam e reforçam a complexidade desse processo. E, articuladas, evidenciaram a interseccionalidade de gênero, raça, classe e geração nas dinâmicas estabelecidas no contexto escolar investigado. Considerando que a subjetividade é construida e influenciada por vários marcadores sociais da diferença, podemos afirmar que o entrelaçamento dinâmico das dimensões de gênero e de raça subsidia o complexo processo de produção das subjetividades das estudantes negras. Dentro da opressão de gênero, por exemplo, se estruturam outras modalidades especificas de opressão, modeladas por outros sistemas sociais que com gênero se interseccionam, neste caso raça, geração e pertencimento social. Com isso, o desafio não é o fortalecimento de opressões, e sim, de que forma as enfrentar a partir de estratégias que entendam como elas se articulam.

\section{Referências}

Bonetti, Alinne de L. 2011. Gênero, poder e feminismos: as arapiracas pernambucanas e os sentidos de gênero da política feminista. Labrys 12 (20): 145-172. https://doi. org/10.21669/tomo.voi12.461.

Brah, Avtar. 2006. Diferença, diversidade, diferenciação. Cadernos Pagu 26: 329- 376. https://doi.org/10.1590/ S0104-83332006000100014.

Britto da Motta, Alda. 2004. Gênero, idades e gerações. Cadernos CRH 17(42): 349-355. http://dx.doi. org/10.9771/ccrh.v17i42.18727. 
Cardoso de Oliveira, Roberto. 1998. O trabalho do antropólogo. São Paulo: Editora UNESP.

Collins, Patricia H. 2016. Aprendendo com a outsider within: a significação sociológica do pensamento negro feminista. Revista Sociedade e Estado 31 (1): 99-127. https://doi.org/10.1590/S0102-69922016000100006.

Collins, Patricia H. 2019. Pensamento feminista negro: conhecimento, consciência e a política do empoderamento. São Paulo: Boitempo.

Gomes, Nilma L. 1996. Educação, raça e gênero: relações imersas na alteridade. Cadernos Pagu 6-7: 67-82. https://periodicos.sbu.unicamp.br/ojs/index.php/ cadpagu/article/view/1862.

Gomes, Nilma L. 2005. Alguns termos e conceitos presentes no debate sobre relações raciais no Brasil: uma breve discussão. In Educação anti-racista: caminhos abertos pela Lei federal $n^{\circ}$ 10.639/03, organizado pela Secretaria de Educação Continuada, Alfabetização e Diversidade, 39-62. Brasilia: MEC.

Gomes, Nilma L. 2012. Movimento negro e educação: ressignificando e politizando a raça. Educação \& Sociedade 33 (120): 727-744. https://doi.org/10.1590/ S0101-73302012000300005.

Gonzales, Lélia. 1984. Racismo e sexismo na cultura brasileira. Revista Ciências Sociais Hoje-Anpocs, 223-244.

Hall, Stuart. 2004. A identidade cultural na pós-modernidade. Rio de Janeiro: DP\& A

Hall, Stuart. 2012. Quem precisa de identidade? In Identidade e diferença: a perspectiva dos estudos culturais, organizado por Tomaz T. da Silva, 103-132. Petrópolis, RJ: Vozes.

Jaccoud, Luciana. 2008. Racismo e república: o debate sobre o branqueamento e a discriminação no Brasil. In As politicas públicas e a desigualdade racial no Brasil: 120 anos após a abolição, organizado por Mário Theodoro, 45-64. Brasilia: IPEA.

Louro, Guacira L. 2000. O corpo educado: pedagogias da sexualidade. Belo Horizonte: Autêntica.

Meneghel, Stela N., Olga Farina e Silvia R. Ramão. 2005 Histórias de resistência de mulheres negras. Estudos Feministas 13 (3): 567-583. https://doi.org/10.1590/ S0104-026X2005000300006.

Nascimento, Elisa L. 2003. O sortilégio da cor: identidade, raça e gênero no Brasil. São Paulo: Summus Editorial.

Nogueira, Oracy. 2006. Preconceito racial de marca e preconceito racial de origem - sugestão de um quadro de referência para a interpretação do material sobre relações raciais no Brasil. Tempo Social 19 (1): 287-308 https://doi.org/10.1590/S0103-20702007000100015.

Ribeiro, Djamila. 2017. O que é lugar de fala? Belo Horizonte: Letramento.

Souza, Neusa S. 1983. Tornar-se negro: as vicissitudes da identidade do negro brasileiro em ascensão social. Rio de Janeiro: Graal.

\section{Cristiane Barbosa Soares}

Mestra e doutoranda em Educação em Ciências pela Universidade Federal do Pampa (Unipampa), em Uruguaiana, RS, Brasil. Professora da Educação Básica no município de Uruguaiana, RS, Brasil.

\section{Alinne de Lima Bonetti}

Doutora em Ciências Sociais pela Universidade Estadual de Campinas (Unicamp), em Campinas, SP, Brasil. Antropóloga. Professora da Universidade Federal de Santa Catarina (Ufsc), em Florianópolis, SC, Brasil.

Os textos deste artigo foram revisados pela Poá Comunicação e submetidos para validação das autoras antes da publicação. 